\title{
Crescimento inicial da berinjeleira sob adubação nitrogenada e fosfatada e irrigada com água de reúso
}

\section{Eggplant early growth under nitrogen and phosphate and irrigated with reuse water}

\author{
Aldair de Souza Medeiros ${ }^{1}$, Reginaldo Gomes Nobre ${ }^{2}$, Eliane da Silva Ferreira ${ }^{3}$, Whalamys Lourenço de Araújo ${ }^{4}$, Manoel \\ Moises Ferreira de Queiroz.
}

\begin{abstract}
RESUMO - A utilização da água vem gerando alguns conflitos devido o aumento da escassez hídrica em todo o mundo, os setores de maior consumo são a agricultura responde por $70 \%$, o setor industrial $22 \%$ e $8 \%$ corresponde ao uso doméstico. Objetivou-se com este trabalho avaliar os efeitos causados pelas doses de nitrogênio e fósforo e a irrigação com água de reúso doméstica pós-tratada em filtro de areia com fluxo intermitente durante o crescimento inicial da berinjeleira na região semiárida paraibana. $\mathrm{O}$ experimento foi realizado em ambiente protegido, no Centro de Ciências e Tecnologia Agroalimentar (CCTA/UFCG), Campus de Pombal - PB, e cujos tratamentos resultaram na combinação de dois fatores: quatro doses de adubação nitrogenada $\left(\mathrm{N}_{1}-3,55 ; \mathrm{N}_{2}-6,2 ; \mathrm{N}_{3}-8,9 ; \mathrm{N}_{4}-11,55 \mathrm{~g}\right.$ de $\left.\mathrm{N} / \mathrm{vaso}\right)$ e quatro doses de adubação fosfatada $\left(\mathrm{P}_{1}-15,28\right.$; $\mathrm{P}_{2}-26,74 ; \mathrm{P}_{3}-38,2 ; \mathrm{P}_{4}-49,66 \mathrm{~g}$ de $\left.\mathrm{P} / \mathrm{vaso}\right)$ correspondendo respectivamente a $40 ; 70 ; 100 ; 130 \%$ conforme indicação de adubação para a cultura da berinjela quando cultivada em vasos, irrigada com água de reúso pós-tratada em filtro de areia intermitente (AR). O delineamento experimental adotado foi o de blocos inteiramente casualizados, com os tratamentos arranjados em esquema fatorial 4 x 4, com quatro repetições. Conclui-se que a prática da irrigação com água de reúso surge como uma fonte hídrica e nutricional para a cultura da berinjela, nas condições edafoclimáticas do semiárido; Doses de 3,55 g de $\mathrm{N}$ e 15,28 g de $\mathrm{P}$ por planta quando se utiliza água de reúso na irrigação de plantas de berinjela são suficientes para suprir as necessidades nutricionais da cultura. A massa fresca da folha de plantas de berinjela decresceu linearmente com o incremento das doses de $\mathrm{N}$ aplicadas. A produção de massa fresca e seca da parte aérea de plantas de berinjela irrigadas com água de reúso com $40 \%$ da adubação com N e P não diferiu das plantas que receberam $100 \%$ indicação de N e P.
\end{abstract}

Palavras-chave: Solanummelongena L., efluente, nitrogênio, fósforo.

ABSTRACT - The use of water has generated some conflicts due to increasing water scarcity around the world, the largest consumer sectors are agriculture accounts for $70 \%$, the industrial sector $22 \%$ and $8 \%$ corresponds to the household. The objective of this study was to evaluate the effects caused by nitrogen and phosphorus and irrigation with reclaimed water posttreated domestic sand filter with intermittent flow during the initial growth of eggplant in Paraíba semi-arid region.The experiment was conducted in a greenhouse, in the Science and Technology Center Agrifood (CCTA / UFCG), Campus de Pombal - PB, and the treatments resulted in the combination of two factors: four doses of nitrogen (N1 - 3.55; N2 - 6.2; N3 8.9; N4 - $11.55 \mathrm{~g} \mathrm{~N} / \mathrm{pot}$ ) and four doses of phosphorus fertilization (P1 - 15.28; P2 - 26.74; P3 - 38.2 ; P4 - 4966 g P / pot) corresponding respectively to $40 ; 70 ; 100 ; 130 \%$ as fertilizer indication for eggplants when grown in pots irrigated with treated wastewater post-intermittent sand filter (AR). The experimental design was a completely randomized design, with treatments arranged in a factorial $4 \times 4$, with four replications. We conclude it the practice of irrigation with reclaimed water emerges as a water and nutrient source for the eggplant crop, soil and weather conditions in the semiarid; Doses of 3,55 $\mathrm{g}$ of $\mathrm{N}$ and $15,28 \mathrm{~g} \mathrm{P}$ per plant when using reclaimed water in irrigation eggplants are sufficient to meet the nutritional needs of the crop. The fresh weight of eggplants sheet decreased linearly with increasing $\mathrm{N}$ rates. The production shoot fresh and dry mass of eggplant plants irrigated with reclaimed water to $40 \%$ of fertilization with $\mathrm{N}$ and $\mathrm{P}$ did not differ from plants that received $100 \%$ of $\mathrm{N}$ and $\mathrm{P}$ indication.

Keywords:. Effluent. Nitrogen. Phosphorus. Solanum melongena L.

\footnotetext{
*Autor para correspondência

Recebido para publicação em 27/06/2015; aprovado em: 10/07/2015

${ }^{1}$ Doutorando em Agronomia (Produção Vegetal), CECA/UFAL, Rio Largo, AL, Brasil. E-mail: aldairmedeiros@ gmail.com

${ }^{2}$ Professor Adjunto III CCTA/UFCG, Pombal, Paraíba, Brasil, E-mails: rgomesnobre@yahoo.com.br; moises@ccta.ufcg.edu.br

${ }^{3}$ Graduanda em Licenciatura em Ciências Agrárias, CCHA/UEPB, Campus IV, Catolé do Rocha, Paraíba, Brasil. E-mail: lianasilva2011 @ gmail.com

${ }^{4}$ Mestre em Horticultura Tropical, CCTA/UFCG, Pombal, Paraíba, Brasil. E-mail: whalamys@ hotmail.com
} 


\section{INTRODUÇÃO}

A agricultura tem sido de grande importância para a economia brasileira, porém vários fatores adversos podem interferir no processo produtivo dos cultivos, entre eles se destacam a escassez hídrica e a fertilidade do solo. Segundo Garcia et al. (2007), a escassez hídrica está ligada a fatores naturais e antrópicos.

A multiplicidade do uso da água pelo homem tem aumentado a sua demanda, causando conflitos principalmente nas regiões áridas e semiáridas de todo o mundo. Segundo dados do Ministério do Meio Ambiente - MMA (2014), a atividade agrícola consume $70 \%$ de toda água captada no país, seguida do setor industrial $(22 \%)$ e do uso doméstico (8\%), tendendo a aumentar, devido à crescente demanda produtiva de alimentos, principalmente para exportação.

O uso doméstico de água em muitas regiões brasileiras tem gerado esgoto que não são tratados regularmente. Sem rede de esgotamento sanitário, grande maioria das populações tem lançado seus dejetos in natura nos mananciais ou no meio ambiente, contaminando suas águas (TONETTI et al., 2010). No entanto, as águas destes mananciais, apesar do risco de contaminação, têm sido muitas vezes utilizadas no abastecimento e irrigação de muitos cultivos agrícolas.

Tendo em vista este fato, uma das alternativas para evitar esse tipo de contaminação, além de suprir a necessidade de água para irrigação de cultivos agrícolas seria o reúso consciente e sustentável de águas provenientes do uso doméstico, uma vez que a atividade agrícola tolera água de qualidade inferior. Esta prática tem sido adotada por vários países, principalmente dos continentes Africanos e Asiáticos.

Para tanto, o pós-tratamento de efluentes em filtro de areia, por exemplo, tem sido um método viável para melhoria da qualidade de água residuária, além de ser bastante simplificado e de baixo custo, onde sua eficiência depende basicamente da intermitência ocorrida durante a aplicação do efluente. O funcionamento do filtro se baseia no período de aplicação do afluente sobre a superfície da areia através de uma tubulação de distribuição. Durante a infiltração do líquido, ocorre uma purificação por mecanismos físicos, químicos e biológicos (AUSLAND et al., 2002), resultando numa água com baixos teores de contaminação, e com concentrações dissolvidas de nutrientes essenciais às plantas como Nitrogênio $(\mathrm{N})$ e Fósforo $(\mathrm{F})$, que estariam prontamente disponíveis para as plantas, podendo assim ser utilizada na agricultura.

Logo, além de suprir a necessidade hídrica dos cultivos agrícolas, a irrigação com água de reuso, contribuiria para a nutrição mineral de plantas, evitando a deficiência de $\mathrm{N}$ nas plantas, que poderia provocar retardo no crescimento, folhas cloróticas, florescimento prematuro e encurtamento do ciclo (TAIZ e ZAIGER, 2004); e facilitando a absorção de P, uma vez que na adubação fosfatada a dosagem, a fonte e a fixação do nutriente interferem neste processo, e, no solo, o elemento possuir pouca mobilidade, sendo absorvido por difusão (ZONTA et al., 2010); além da economia com gastos com fertilizantes.

Entretanto, as concentrações de nutrientes na água de reuso são baixas, sendo necessária uma complementação com doses de adubação nitrogenada e fosfatada. Porém, pode ocorrer o excesso destes nutrientes, o que provocaria, no caso do $\mathrm{N}$, alongamento no desenvolvimento da parte aérea da planta e diminuição do crescimento radicular (TAIZ e ZAIGER, 2004).

Neste contexto, objetivou-se com este trabalho avaliar os efeitos de doses de nitrogênio e fósforo combinadas com a irrigação com água de reúso doméstica, pós-tratada em filtro de areia com fluxo intermitente durante o crescimento inicial da berinjeleira, solanácea perene (porém cultivada como anual), arbustiva com caule semi-lenhoso e resistente a patógenos e temperaturas (FILGUEIRA, 2003).

\section{MATERIAL E MÉTODOS}

$\mathrm{O}$ experimento foi realizado em ambiente protegido (casa de vegetação), no Centro de Ciências e Tecnologia Agroalimentar da Universidade Federal de Campina Grande (UFCG), Campus de Pombal - PB. A cidade de Pombal está situada na região Oeste do Estado da Paraíba, localizando-se as margens da BR-230, sob as coordenadas geográficas $06^{\circ} 46^{\prime}$ de latitude sul, $37^{\circ} 48^{\prime}$ de longitude oeste e altitude de 148 m (BELTRÃO et al., 2005). A classificação do clima da região, conforme Koppen é do tipo BSh, representando clima semiárido quente e seco, a precipitação média na região é de aproximadamente $750 \mathrm{~mm}$ ano $^{-1}$, com evaporação média anual de $2000 \mathrm{~mm}$.

A temperatura média observada durante os meses de condução da pesquisa foi de $33,4{ }^{\circ} \mathrm{C}$ e a umidade relativa média de 44,5\%.

Os tratamentos resultaram na combinação de dois fatores: quatro doses de nitrogênio $\left(\mathrm{N}_{1}-3,55 ; \mathrm{N}_{2}-6,2 ; \mathrm{N}_{3}\right.$ 8,$9 ; \mathrm{N}_{4}-11,55 \mathrm{~g}$ de $\left.\mathrm{N} / \mathrm{vaso}\right)$ e quatro doses de fósforo $\left(\mathrm{P}_{1}-\right.$ 15,$28 ; \mathrm{P}_{2}-26,74 ; \mathrm{P}_{3}-38,2 ; \mathrm{P}_{4}-49,66 \mathrm{~g}$ de $\mathrm{P} /$ vaso), correspondendo a $40 ; 70 ; 100 ; 130 \%$, respectivamente, conforme indicação de adubação para a cultura da berinjela quando cultivada em vasos, sugerida por Malavolta (1980), irrigada com água de reúso pós-tratada em filtro de areia com fluxo intermitente (AR).

O delineamento experimental adotado foi o de blocos inteiramente casualizados, com os tratamentos arranjados em esquema fatorial $4 \times 4$, com quatro repetições, perfazendo o total de 64 unidades experimentais, em fileiras simples espaçadas 1,0 m entre fileiras e $0,5 \mathrm{~m}$ entre plantas dentro de cada fileira.

Utilizou-se a cultivar de berinjela Embú. Foram utilizados para condução das plantas, recipientes plásticos com $20 \mathrm{~L}$ de capacidade, preenchidos com $1 \mathrm{~kg}$ de brita $\left(\mathrm{n}^{\circ}\right.$ zero) cobrindo a base do vaso seguido por $20 \mathrm{~kg}$ de material de solo, classificado como franco-arenoso, não salino e não sódico, o material coletado foi proveniente do município de Pombal - PB. Após seco ao ar, destorroado e passado em peneira de malha de $2,0 \mathrm{~mm}$, o solo foi encaminhado ao Laboratório de Irrigação e Salinidade (LIS) do Centro de Tecnologia e Recursos naturais (CTRN) da Universidade Federal de Campina Grande (UFCG), cujas características químicas e físicas (Tabela 1) foram obtidas conforme metodologias recomendadas pela Embrapa (1997). Os vasos possuíam um orifício com uma mangueira transparente em sua base conectado a uma garrafa plástica para coleta de água drenada e estimativa do consumo de água pela planta. 
Tabela 1. Atributos químicos e físicos do solo utilizado no experimento.

\begin{tabular}{|c|c|c|c|}
\hline Químicos & Valor & Físicos & Valor \\
\hline pH (Extrato de Saturação) & 7,74 & Areia $\left(\mathrm{g} \mathrm{kg}_{-}{ }^{1}\right)$ & 678,1 \\
\hline P Assimilável (mg/100g) & 4,61 & Silte $\left(\mathrm{g} \mathrm{kg-}^{1}\right)$ & 181,5 \\
\hline $\mathrm{K}^{+}\left(\mathrm{cmol}_{\mathrm{c}} \mathrm{kg}^{-1}\right)$ & 0,30 & Argila $\left(\mathrm{g} \mathrm{kg}_{-}{ }^{1}\right)$ & 131,4 \\
\hline $\mathrm{Na}^{+}\left(\mathrm{cmol}_{\mathrm{C}} \mathrm{kg}^{-1}\right)$ & 0,73 & Classificação Textural & Arenoso \\
\hline $\mathrm{Ca}^{2+}\left(\mathrm{cmol}_{\mathrm{c}} \mathrm{kg}^{-}\right)$ & 5,27 & Densidade do Solo $\left(\mathrm{g} / \mathrm{cm}^{3}\right)$ & 1,26 \\
\hline $\mathrm{Mg}^{2+}\left(\mathrm{cmol}_{\mathrm{c}} \mathrm{kg}^{-1}\right)$ & 2,37 & Densidade de Partículas $\left(\mathrm{g} / \mathrm{cm}^{3}\right)$ & 2,71 \\
\hline $\mathrm{H}+\mathrm{Al}\left(\mathrm{cmol}_{\mathrm{c}} \mathrm{kg}^{-1}\right)$ & 0,00 & Porosidade $(\%)$ & 53,50 \\
\hline CTC $\left(\mathrm{cmol}_{\mathrm{c}} \mathrm{kg}^{-1}\right)$ & 8,67 & & \\
\hline M.O. $\left(\mathrm{g} . \mathrm{kg}^{-1}\right)$ & 9,3 & Unidade - \% & \\
\hline $\mathrm{N}\left(\mathrm{g} . \mathrm{kg}^{-1}\right)$ & 0,5 & Natural $\left(\mathrm{g} \mathrm{kg}^{-1}\right)$ & 8,0 \\
\hline C.O. $\left(\mathrm{g} . \mathrm{kg}^{-1}\right)$ & 5,4 & & \\
\hline $\mathrm{CE}_{\mathrm{es}}\left(\mathrm{dm}^{-1}\right)$ & 2,24 & $33,4 \mathrm{kPa}-\mathrm{g} \mathrm{kg}^{-1}$ & 132,6 \\
\hline Percentagem de Saturação & 23,33 & & \\
\hline $\operatorname{RAS}\left(\mathrm{mmol}_{\mathrm{c}} \mathrm{L}^{-1}\right)$ & 3,23 & $1519,9 \mathrm{kPa}-\mathrm{g} \mathrm{kg}^{-1}$ & 58,7 \\
\hline PSI & 8,42 & Água Disponível $\mathrm{g} \mathrm{kg}^{-1}$ & 73,9 \\
\hline
\end{tabular}

Depois de acondicionado nos vasos o solo foi colocado em capacidade de campo (CC), através do método de saturação por capilaridade, seguido por drenagem livre, utilizando-se a água de reúso.

As mudas de berinjeleira foram produzidas em bandejas de poliestireno expandido (Isopor) de 128 células, utilizando-se o substrato comercial a base de casca de pinus, húmus e vermiculita, com duas sementes por célula. A emergência das plântulas iniciou-se no sexto dia após o semeio (DAS) e prolongou-se até o décimo dia; aos 25 DAS foi realizado o transplantio de três mudas por vaso e, aos 9 dias após o transplantio (DAT) realizou o primeiro desbaste, deixando apenas duas plantas por vaso, as com melhor vigor; aos 17 DAT foi realizado o segundo desbaste, a partir do qual, os dados de crescimento inicial das plantas foram analisados.

A fonte de nitrogênio utilizada foi à ureia $(45 \%$ de $\mathrm{N})$. Como fonte de fósforo, utilizou-se super fosfato simples, sendo incorporados como adubação de fundação trinta dias antes do transplantio, devido o período que o nutriente demora em se tornar disponível as plantas.
Os tratos culturais realizados durante o ciclo da cultura foram: controle fitossanitário, principalmente de moscabranca (Bemisiassp.), com aplicações de inseticida com aplicação no solo via água de irrigação (100 ml/vaso na concentração $1 \mathrm{~g} / \mathrm{L}$ ); aplicou-se preventivamente fungicida (100 ml/vaso na concentração $3 \mathrm{~g} / \mathrm{L}$ ); realizou-se ainda capinas manuais com frequência semanal para o controle de plantas daninhas.

A água de reúso doméstica, utilizada no experimento, foi proveniente de pias, chuveiros e sanitários dos banheiros localizados no prédio da central de aulas II, da Universidade Federal de Campina Grande, campus de Pombal - PB, coletada por tubulações e depositada em um tanque séptico, por onde passou por um tratamento anaeróbio natural; na sequência, conectou-se um tubo na saída do tanque ligado a um recipiente plástico com $500 \mathrm{~L}$ de capacidade, funcionando como reservatório de distribuição do efluente. Essa distribuição era feita por tubulações até os três filtros com intermitências diferentes, o efluente produzido era armazenado em recipiente plástico com capacidade de $500 \mathrm{~L}$ (Figura 1).

Figura 1. Esquema da disposição do sistema de tratamento do esgoto com filtros de areia com fluxo intermitente.

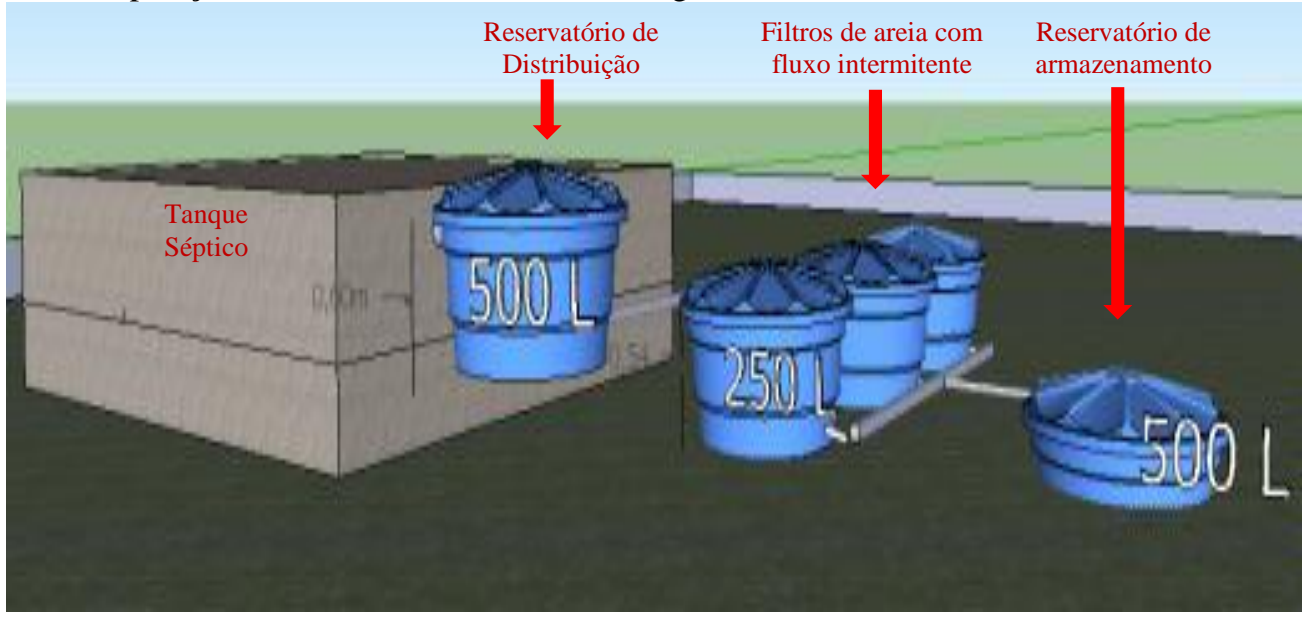

Os filtros foram construídos adaptando recipientes plásticos com capacidade de $250 \mathrm{~L}$ cada; na parte inferior dos recipientes continha uma camada de $10 \mathrm{~cm}$ com brita $\left(\mathrm{n}^{\circ} 1\right)$, depois $50 \mathrm{~cm}$ de areia e na parte superior mais uma camada de $5 \mathrm{~cm}$ com brita, com o intuito de uniformizar o fluxo.

Foram analisados os parâmetros físico-químicos da água de reúso. As análises foram realizadas semanalmente e 
as amostras coletadas em dois pontos distintos: efluentes do tanque séptico, e do reservatório de armazenamento, as amostras de efluente eram encaminhadas ao laboratório de análises de água da UFCG campus de Pombal - PB. Na Tabela 2, encontram-se os valores médios das características do efluente antes e após o pós-tratamento.

Tabela 2. Características físico-químicas do efluente nos diferentes pontos de coleta, caixa de distribuição $\left(\mathrm{P}_{1}\right)$, reservatório de armazenamento $\left(\mathrm{P}_{2}\right)$. Pombal - PB, 2015.

\begin{tabular}{ccc}
\hline Parâmetros & $\mathbf{P}_{\mathbf{1}}$ & $\mathbf{P}_{\mathbf{2}}$ \\
\hline OD & $0,9(\mathrm{mg} / \mathrm{L})$ & $6,66(\mathrm{mg} / \mathrm{L})$ \\
$\mathrm{T}$ & $30,1\left({ }^{\circ} \mathrm{C}\right)$ & $30,0\left({ }^{\circ} \mathrm{C}\right)$ \\
Turb. & $9,16(\mathrm{NTU})$ & $12,62(\mathrm{NTU})$ \\
pH & 8,54 & 7,31 \\
$\mathrm{CE}$ & $0,066(\mathrm{dS} / \mathrm{m})$ & $0,069(\mathrm{dS} / \mathrm{m})$ \\
$\mathrm{Cor}$ & 160,7 & 90,76 \\
$\mathrm{DT}$ & $55,27(\mathrm{mg} \mathrm{CaCo} / \mathrm{L})$ & $102,40\left(\mathrm{mg} \mathrm{CaCo}_{3} / \mathrm{L}\right)$ \\
$\mathrm{Ca}$ & $17,25(\mathrm{mg} / \mathrm{L})$ & $47,5(\mathrm{mg} / \mathrm{L})$ \\
$\mathrm{Mg}$ & $38,02(\mathrm{mg} / \mathrm{L})$ & $54,80(\mathrm{mg} / \mathrm{L})$ \\
$\mathrm{Cl}$ & $104,3(\mathrm{mg} \mathrm{Cl} / \mathrm{L})$ & $90,76(\mathrm{mg} \mathrm{Cl} / \mathrm{L})$ \\
$\mathrm{P}$ & $0,2612(\mathrm{mg} / \mathrm{L})$ & $0,7047(\mathrm{mg} / \mathrm{L})$ \\
$\mathrm{N}$ & $0,00015(\mathrm{mg} / \mathrm{L})$ & $0,00007(\mathrm{mg} / \mathrm{L})$ \\
$\mathrm{Na}$ & $0,0006(\mathrm{mg} / \mathrm{L})$ & $0,0021(\mathrm{mg} / \mathrm{L})$ \\
$\mathrm{K}$ & $0,0086(\mathrm{mg} / \mathrm{L})$ & $0,008(\mathrm{mg} / \mathrm{L})$ \\
\hline
\end{tabular}

OD - oxigênio dissolvido; T - temperatura; Turb. - turbidez; $\mathrm{pH}$ - (potencial hidrogeniônico); CE - condutividade elétrica; DT - dureza total; Ca - cálcio; Mg - magnésio, $\mathrm{Cl}^{-}$- cloretos; $\mathrm{P}$ - fósforo; $\mathrm{N}$ - nitrogênio; $\mathrm{Na}$ - sódio; $\mathrm{K}$ - potássio

A água de reuso tratada era coletada do reservatório de armazenamento após os filtros de areia com fluxo intermitente, armazenada em depósitos plásticos com capacidade de 20 L. Após o transplantio, realizaram-se irrigações diárias. $\mathrm{O}$ volume de água aplicado na irrigação visava manter o solo em capacidade de campo, sendo determinado através da diferença do volume aplicado pelo drenado.

Aos 17 DAT analisou-se, a partir da planta coletada de cada vaso,a altura de planta (AP) em cm, diâmetro caulinar (DC) em mm, número de Folhas (NF), e área foliar (AF) em $\mathrm{cm}^{2}$.

A AP foi definida mensurando-se a distância entre o colo da planta e o ápice da haste principal; o DC foi determinado a $3 \mathrm{~cm}$ do colo das plantas com o auxílio de paquímetro digital; a quantificação do NF foi feita considerando-se apenas as folhas com no mínimo de 50\% de sua área fotossinteticamente ativa e a largura mínima de $1 \mathrm{~cm}$ e a AF foi obtida segundo metodologia proposta por Maldaner et al. (2009) conforme Eq:

$$
\mathrm{AF}=0,08841 \times \mathrm{L}^{1,9862}
$$

em que:
$\mathrm{AF}=$ área foliar em $\mathrm{cm}^{2}$,

$\mathrm{L}=$ largura das folhas em $\mathrm{cm}$.

As plantas foram separadas em caule e folhas, e, utilizando balança com precisão digital, determinou-se a matéria fresca do caule (MFC) e da folha (MFF) em g. Na sequência o material foi colocado em estufa de secagem $65^{\circ} \mathrm{C}$, até obtenção de massa constante, com posterior obtenção da matéria seca do caule (MSC) e das folhas (MSF) em g.

Os dados obtidos forma submetidos a análise de variância pelo Teste $\mathrm{F}$, e no caso de significância, realizaramse análise de regressão linear e polinomial utilizando-se o software estatístico SISVAR 5.3 (FERREIRA, 2008).

\section{RESULTADOS E DISCUSSÃO}

As variáveis morfofisiológicas da berinjeleira "Embú" cultivada em ambiente protegido: altura de planta, diâmetro caulinar e número de folhas não foram influenciados de forma significativa pelas doses de nitrogênio e fósforo. Por outro lado, a variável área foliar foi influenciada de forma significativa apenas pelas doses de nitrogênio a $1 \%$ de probabilidade (Tabela 3).

Tabela 3. Resumo das análises de variância das variáveis, altura de planta, diâmetro caulinar, número de folhas e área foliar de plantas de berinjela sob adubação nitrogenada e fosfatada e irrigação com água de reúso aos 17 dias após o trasplantio. Pombal $-\mathrm{PB}, 2015$.

\begin{tabular}{lccccc}
\hline & & \multicolumn{3}{c}{ Quadrados Médios } \\
\cline { 3 - 6 } Fonte de Variação & GL & AP & DC & NF & AF \\
\hline Nitrogênio (N) & 3 & $0,74^{\mathrm{ns}}$ & $0,13^{\mathrm{ns}}$ & $0,05^{\mathrm{ns}}$ & $7073,3^{*}$ \\
Regressão Linear & 1 & $0,73^{\mathrm{ns}}$ & $0,34^{\mathrm{ns}}$ & $0,00^{\mathrm{ns}}$ & $19544,2^{* *}$ \\
Regressão Quadrática & 1 & $1,23^{\mathrm{ns}}$ & $0,00^{\mathrm{ns}}$ & $0,14^{\mathrm{ns}}$ & $1532,8^{\mathrm{ns}}$ \\
Fósforo (P) & 3 & $1,76^{\mathrm{ns}}$ & $0,07^{\mathrm{ns}}$ & $0,51^{\mathrm{ns}}$ & $1764,1^{\mathrm{ns}}$ \\
Regressão Linear & 1 & $0,21^{\mathrm{ns}}$ & $0,18^{\mathrm{ns}}$ & $0,28^{\mathrm{ns}}$ & $543,6^{\mathrm{ns}}$ \\
Regressão Quadrática & 1 & $0,06^{\mathrm{ns}}$ & $0,02^{\mathrm{ns}}$ & $0,14^{\mathrm{ns}}$ & $831,9^{\mathrm{ns}}$ \\
Interação (N x P) & 9 & $1,03^{\mathrm{ns}}$ & $0,09^{\mathrm{ns}}$ & $1,21^{\mathrm{ns}}$ & $1404,4^{\mathrm{ns}}$ \\
Blocos & 3 & 4,26 & 0,40 & 1,34 & 3322,5 \\
Resíduo & 45 & 2,57 & 0,18 & 1,67 & 29,59 \\
\hline CV (\%) & & 20,53 & 13,33 & 17,34 & 29,59 \\
\hline
\end{tabular}

ns, ${ }^{* *},{ }^{*}$ - não significativo, significativo a $\mathrm{p}<0,01$ e $\mathrm{p}<0,05$,respectivamente, pelo teste F; GL - número de graus de liberdade; C. V. - coeficiente de variação. 
Na figura 2, constatam-se a tendência da área foliar (AF) da berinjeleira em função das doses de nitrogênio $(\mathrm{N})$. Verifica-se que o aumento da dose de $\mathrm{N}$ promoveu um decréscimo linear conforme se aumentava as doses.

Havendo redução de $0,22 \%$ por aumento unitário da dose de $\mathrm{N}$ aplicado, denotando-se decréscimos de $19,87 \%$ na AF das plantas quando receberam a dose de $130 \%$ em relação as que receberam $40 \%$ de N. Entende-se, portanto que, certamente a quantidade de $\mathrm{N}$ aplicado com a dose de $3,55 \mathrm{~g}$ (40\%) foi suficiente para suprir as necessidades nutricionais das plantas durante o período de avaliação, e/ou a quantidade de $\mathrm{N}$ diluída na água de reúso contribuiu para suprir a necessidade elementar desse nutriente pela planta. Na medida em que se aumentavam as doses $\mathrm{N}$, juntamente com o $\mathrm{N}$ presente na água de reúso ocorria reduções na $\mathrm{AF}$ das plantas.

Essas reduções eram decorrentes da disponibilidade em excesso do nutriente $\mathrm{N}$ ocorrido pelo aumento da dose juntamente com a quantidade presente na água de reúso utilizada na irrigação das plantas. Silva et al. (2013), avaliando o uso de água de reúso na cultura do algodoeiro, observaram aumento na área foliar das plantas quando irrigadas com a água de reúso em comparação as que eram irrigadas com água de abastecimento.

Figura 2. Área foliar de plantas de berinjela em função de doses de nitrogênio e irrigação com água de reuso aos 17 DAT

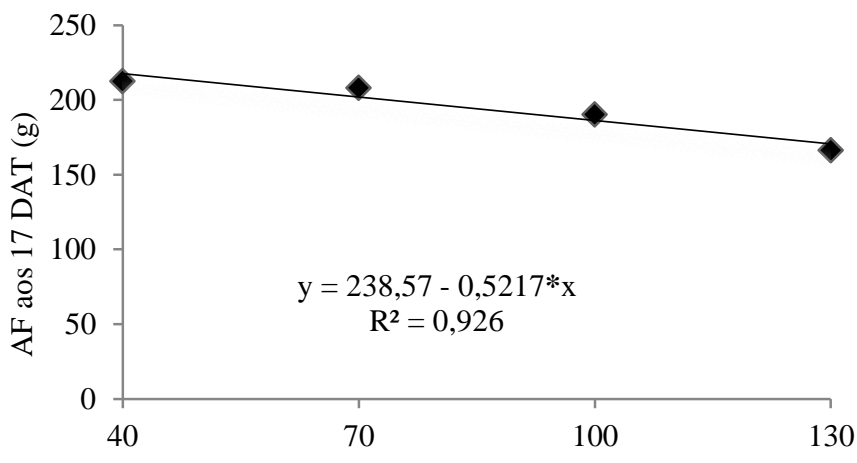

Dose de Nitrogênio (\% da recomendação)

Conforme análise de variância verifica-se efeito significativo $(\mathrm{p}<0,05)$ do fator doses de nitrogênio $(\mathrm{N})$ apenas sobre a massa fresca da folha. As doses de fósforo (P) assim como a interação entre os fatores estudados (doses de $\mathrm{N}$ e de P) não promoveram efeito significativo sobre nenhuma variável estudada (Tabela 4).

Tabela 4. Resumo das análises de variância das variáveis, massa fresca de caule, massa fresca de folhas, massa seca de caule e massa seca de folhas de plantas de berinjela sob adubação nitrogenada e fosfatada e irrigação com água de reúso aos 17 dias após o transplantio. Pombal - PB, 2015.

\begin{tabular}{|c|c|c|c|c|c|}
\hline \multirow[b]{2}{*}{ Fonte de Variação } & \multirow[b]{2}{*}{ GL } & \multicolumn{4}{|c|}{ Quadrados Médios } \\
\hline & & MFC & MFF & MSC & MSF \\
\hline Nitrogênio $(\mathrm{N})$ & 3 & $0,15^{\mathrm{ns}}$ & $8,93^{\text {ns }}$ & $0,002^{\mathrm{ns}}$ & $0,09^{\mathrm{ns}}$ \\
\hline Regressão Linear & 1 & $0,31^{\mathrm{ns}}$ & $24,25^{*}$ & $0,007^{\mathrm{ns}}$ & $0,21^{\mathrm{ns}}$ \\
\hline Regressão Quadrática & 1 & $0,10^{\mathrm{ns}}$ & $1,58^{\mathrm{ns}}$ & $0,001^{\mathrm{ns}}$ & $0,04^{\mathrm{ns}}$ \\
\hline Fósforo (P) & 3 & $0,26^{\mathrm{ns}}$ & $2,54^{\mathrm{ns}}$ & $0,003^{\mathrm{ns}}$ & $0,07^{\mathrm{ns}}$ \\
\hline Regressão Linear & 1 & $0,17^{\mathrm{ns}}$ & $3,12^{\mathrm{ns}}$ & $0,001^{\mathrm{ns}}$ & $0,03^{\mathrm{ns}}$ \\
\hline Regressão Quadrática & 1 & $0,00^{\mathrm{ns}}$ & $0,00^{\mathrm{ns}}$ & $0,001^{\mathrm{ns}}$ & $0,0^{\mathrm{ns}}$ \\
\hline Interação $(\mathrm{N} x \mathrm{P})$ & 9 & $0,07^{\mathrm{ns}}$ & $1,10^{\mathrm{ns}}$ & $0,001^{\mathrm{ns}}$ & $0,01^{\mathrm{ns}}$ \\
\hline Blocos & 3 & 0,40 & 5,64 & 0,005 & 0,04 \\
\hline Resíduo & 45 & 0,24 & 3,54 & 0,003 & 0,07 \\
\hline $\mathrm{CV}(\%)$ & & 39,56 & 31,46 & 38,38 & 34,91 \\
\hline
\end{tabular}

Doses crescentes de $\mathrm{N}$ promoveram decréscimo linear sobre a MFF aos 17 DAT (Figura 3), ocorrendo redução na ordem de $0,24 \%$ por aumento unitário da dose de $\mathrm{N}$ aplicada, ou seja, decréscimo de $21,49 \%$ na MFF das plantas adubadas com $130 \%$ de $\mathrm{N}$ em comparação com as que receberam $40 \%$ de N. Denota-se que, possivelmente, esse fato tenha ocorrido devido ao $\mathrm{N}$ presente na água de irrigação ter suprido a necessidade de $\mathrm{N}$ da planta e/ou devido à soma do $\mathrm{N}$ contido na água de reúso com a da adubação ter promovido estresse na planta, contribuindo com a redução da MFF, entretanto, não foi observado sintomas externo nas plantas. Tendência semelhante foi observada por Araújo et al. (2011) avaliando a resposta da alface a adubação nitrogenada, que constataram um decréscimo linear na massa fresca da parte aérea (MFPA) da cultura com a aplicação de $\mathrm{N}$ via fertirrigação, outrossim, o tratamento sem a adição de $\mathrm{N}$ obteve maior valor desta variável. Creditando o ocorrido, na presença da matéria orgânica no solo, que deve ter suprido a necessidade da cultura em $\mathrm{N}$, abstraindo o uso do adubo químico nitrogenado. 
Figura 3. Massa fresca de folhas de plantas de berinjela em função da adubação nitrogenada e irrigação com água de reúsoaos 17 DAT

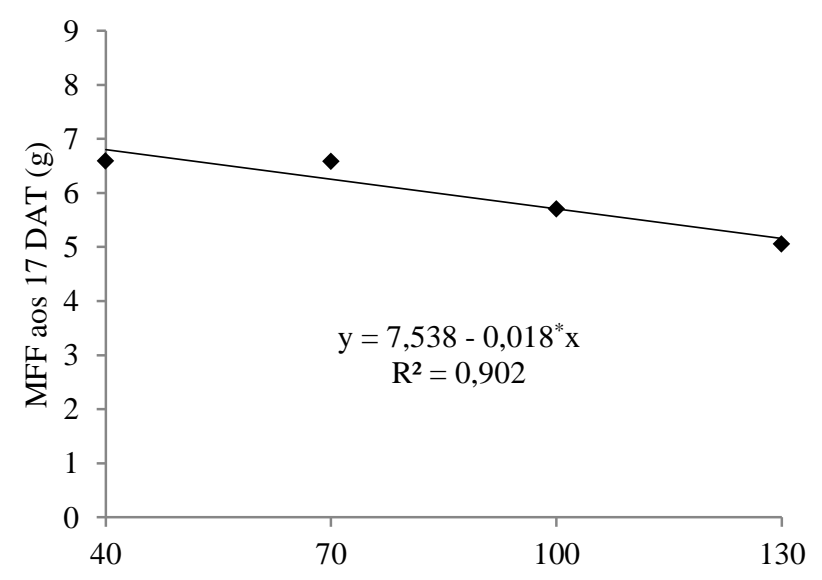

Dose de Nitrogênio (\% da recomendação)

Em estudos com a cultura do girassol, Oliveira et al. (2012) observaram não haver efeito significativo da adubação nitrogenada sobre MFF, MFC e MFPA, como também não constataram efeito significativo na interação $\mathrm{N}$ e os níveis de água disponível. Sandriet al. (2006) avaliaram a composição química da parte aérea da alface, cv. "Elisa" irrigada com água de reúso tratada e água de abastecimento, observaram não haver efeito significativo do $\mathrm{N}$ entre os tratamentos. Relatando que o maior valor de $\mathrm{N}$ na $\mathrm{AR}$ não influenciou na absorção e no acúmulo de $\mathrm{N}$ na parte aérea da alface, com valores muito próximos aos obtidos na AA. Com a mesma cultura Lima et al. (2005) obtiveram maiores produtividades em massa seca com à fertirrigação utilizando água de reuso tratada. Esses resultados corroboram com os obtidos nesta pesquisa.

Nesse sentido, percebe-se uma similaridade nos resultados obtidos por alguns autores aos encontrados na pesquisa, redução na MFF com o aumento nas doses de $\mathrm{N}$, possivelmente é decorrente ao efeito tóxico ocasionado pelo excesso desse nutriente nas plantas, como também, aumento na salinidade devido ao excesso de íons no solo, já para as variáveis MFC, MSF, MSC possivelmente, está relacionado com o período de coleta das plantas (17 DAT). Certamente, os nutrientes presentes na AR doméstica supriu as necessidades nutricionais da cultura nesse período, em virtude da dose mínima de $\mathrm{N}$ e $\mathrm{P}$ obter valores semelhantes às doses recomendadas.

De acordo com Leon e Cavallini (1999), quando ocorre irrigação das culturas com água de reuso tratada, obtêm-se maior produtividade quando comparadas a irrigação com água potável e fertilização química aplicada no solo, em virtude da grande quantidade de nutrientes e à alta concentração de matéria orgânica que retém umidade no solo e contribui na fixação de nutrientes necessários à nutrição das plantas.

Para a cultura do pimentão Souza et al. (2006), observaram não haver diferença significativa da fitomassa, área foliar e a produtividade nos tratamentos com adubação completa, adubação orgânica com vermicomposto e irrigação com água de reúso. Recomendando o uso do efluente como alternativa para reúso, do ponto de vista nutricional.

Estudos observando a resposta da cultura do girassol a irrigação com água de reúso e adubação orgânica feitos por Nobre et al. (2010), constataram que a água residuária beneficiou a altura de planta, fitomassa seca da parte aérea, diâmetro de capítulo externo e interno, fitomassa fresca de capítulo, número de aquênio por capítulo e fitomassa de aquênio por planta. Os autores recomendam o efluente doméstico como fonte viável ao suprimento hídrico das culturas agrícolas.

\section{CONCLUSÕES}

A prática da irrigação com água de reúso surge como uma fonte hídrica e nutricional para a cultura da berinjela, nas condições edafoclimáticas do semiárido.

Doses de 3,55 g de $\mathrm{N}$ e 15,28 g de P por planta quando se utiliza água de reúso na irrigação de plantas de berinjela são suficientes para suprir as necessidades nutricionais da cultura.

A massa fresca da folha de plantas de berinjela decresceu linearmente com o incremento das doses de $\mathrm{N}$ aplicadas.

A produção de massa fresca e seca da parte aérea de plantas de berinjela irrigadas com água de reúso com $40 \%$ da adubação com $\mathrm{N}$ e $\mathrm{P}$ não diferiu das plantas que receberam $100 \%$ da indicação de N e P.

\section{REFERÊNCIAS BIBLIOGRÁFICAS}

ARAÚJO, W. F.; SOUSA, K. T. S.; VIANA, T. V. A.; AZEVEDO, B. M.; BARROS, M. M.; MARCOLINO, E. Resposta da alface a adubação nitrogenada. Revista Agro@mbiente. v.5,n.1, p.12-17, 2011.

AUSLAND, G.; STEVIK, T. K.; HANSSEN, J. F.; KOHLER, J. C.; JENSSEN, P. D. Intermittent filtration of wastewater - removal of fecal coliforms and fecal streptococci. Water Research. v.36, n.14, p.3507-3516, 2002.

Beltrão, B. A. Diagnóstico do município de Pombal. Projeto cadastro de fontes de abastecimento por água subterrânea. Ministério de Minas e Energia/CPRM/PRODEM. Recife, 2005. 23p.

EMBRAPA. Centro Nacional de Pesquisa de Solos (Rio de Janeiro, RJ). Manual de métodos de análise de solo. 2.ed. ver. Atual. Rio de Janeiro. 1997, 212 p. 
FERREIRA, D. F. SISVAR: um programa para análise e ensino de estatística. Revista Symposium, v. 6, p. 3641, 2008.

FILGUEIRA, F. A. R. Novo Manual de olericultura: agrotecnologia moderna na produção e comercialização de hortaliças. Viçosa: UVF, 2003.

GARCIA, A. V.; OLIVEIRA, E. C. A.; SILVA, G. P.; COSTA, P. P.; OLIVEIRA, L. A. Disponibilidade hídrica e volume de água outorgado na micro-bacia do ribeirão abóbora, município de rio verde, estado de Goiás. Caminhos de Geografia. v.8, n.22, p.97-106, 2007.

LEON, S. G.; CAVALlinI, J. M. Tratamento e uso de águas residuárias. Campina Grande: UFPB, 1999. $110 \mathrm{p}$.

LIMA, S. M. S.; HENRIQUE, I. N.; CEBALLOS, B. S. O.; JOSÉ T. DE SOUSA, J. T.; ARAÚJO, H. W. C. Qualidade sanitária e produção de alface irrigada com esgoto doméstico tratado. Revista Brasileira de Engenharia Agrícola e Ambiental. v.9, (Suplemento), p.21-25, 2005.

MALDANER, I. C.; GUSE, F. I.; STRECK, N. A.; HELDWEIN, A. B.; LUCAS, D. D. P.; LOOSE, L. H. Filocrono, área foliar e produtividade de frutos de berinjela conduzidas com uma e duas hastes por planta em estufa plástica. Ciência Rural. v.39, n.3, p.671-677, 2009.

MINISTÉRIO DO MEIO AMBIENTE - MMA: Secretaria de Recursos Hídricos. Disponível em: http://meioambiente.gov.br. Acesso em: 24 dez. 2014.

NOBRE, R. G.; GHEYI, H. R.; SOARES, F. A. L.; ANDRADE, L. O.; NASCIMENTO, E. C. S. Produção do girassol sob diferentes lâminas com efluentes domésticos e adubação orgânica. Revista Brasileira de Engenharia Agrícola e Ambiental. v.14, n.7, p.747754,2010

OLIVEIRA, J. T. L.; CHAVES, L. H. G.; CAMPOS, V. B.; SANTOS JÚNIOR, J. A.; GUEDES FILHO, D. H. Fitomassa de girassol cultivado sob adubação nitrogenada e níveis de água disponível no solo. Revista Brasileira de Agricultura Irrigada. v.6, n. 1, p.23-32, 2012.

SANDRI, D.; MATSURA, E. E.; TESTEZLAF, R. Teores de nutrientes na alface irrigada com água residuária aplicada por sistemas de irrigação. Revista Engenharia Agrícola. v.26, n.1, p.45-57, 2006.

SILVA, L. V. B. D.; LIMA, V. L. A.; SILVA, V. N. B.; SOFIATTI, V.; PEREIRA, T. L. P. Torta de mamona residual e irrigação com efluente sobre crescimento e produção de algodoeiro herbáceo. Revista Brasileira de Engenharia Agrícola e Ambiental. v.17, n.12, p.12641270, 2013.
SOUZA, J. T.; CEBALlOS, B. S. O.; HENRIQUE, I. N.; DANTAS, J. P.; LIMA, S. M. S. Reúso de água residuária na produção de pimentão (Capsicumannuum L.). Revista Brasileira de Engenharia Agrícola e Ambiental. v.10, n.1, p.89-96, 2006.

TAIZ, L.;\& ZEIGER, E. Fisiologia vegetal. Porto Alegre: ARTMED, 2004.

TONETTI, A. L.; CORAUCCI FILHO, B.; BERTONCINI, E. I.; OLIVEIRA, R. A.; STEFANUTTI, R. Avaliação de um sistema simplificado de tratamento de esgotos visando a utilização em áreas rurais. Revista Brasileira de Engenharia Agrícola e Ambiental. Campina Grande, v. 14, n. 2, p. 227-234, 2010.

ZONTA, T. T.; BISCARO, G. A.; TOSTA, M. S.; MEDEIROS, L. F.; SORATTO, R. P.; TOSTA, P. A. F. Doses de superfosfato simples na produção da berinjela 'ciça' em Cassilândia (MS) Brasil. Agropecuária Científica no Semi-Árido. v.06, n.01, p.07-13, 2010. 